\title{
Pemetrexed plus dendritic cells as third-line therapy for metastatic esophageal squamous cell carcinoma
}

This article was published in the following Dove Press journal:

OncoTargets and Therapy

29 June 2016

Number of times this article has been viewed

\author{
Bin Zhangl,* \\ Rui $\mathrm{Li}^{2,3, *}$ \\ Chun-Xiao Chang ${ }^{2,3}$ \\ Yong $\mathrm{Han}^{2,3}$ \\ Sheng-Bin Shi ${ }^{2,3}$ \\ Jing Tian ${ }^{2,3}$ \\ 'Department of Medical Oncology, \\ Shandong Ji Ning First People's \\ Hospital, ${ }^{2}$ Department of Medical \\ Oncology, Shandong Cancer Hospital, \\ Shandong University, Shandong \\ ${ }^{3}$ Department of Medical Oncology, \\ Shandong Cancer Hospital and \\ Institute, Shandong Academy of \\ Medical Sciences, Jinan, People's \\ Republic of China \\ *These authors contributed equally \\ to this work
}

\begin{abstract}
This study was conducted to evaluate the toxicity and efficacy of pemetrexed plus dendritic cells (DCs) when administered as third-line treatment for metastatic esophageal squamous cell carcinoma (ESCC). All patients in the study group had previously failed first-line treatment with 5-fluorouracil and cisplatin-based regimens, as well as second-line treatment with taxane-based regimens. A total of 31 patients were treated with pemetrexed $\left(500 \mathrm{mg} / \mathrm{m}^{2}\right)$ plus DCs on day 1 , every 3 weeks. DCs were given for one cycle of 21 days. Thirty patients were evaluated for their response. No patient had a complete response, three patients $(10.0 \%)$ had a partial response, ten patients $(33.3 \%)$ had stable disease, and 17 patients $(56.7 \%)$ had progressive disease. The overall response rate was $10.0 \%$. The median progression-free survival (PFS) time was 2.9 months (95\% CI, 2.7-3.2), and the median overall survival (OS) time was 7.1 months (95\% CI, 6.4-7.9). The median PFS and OS times among patients with high and low levels of miR-143 expression in their blood serum were significantly different: median PFS times $=3.2$ months $(95 \% \mathrm{CI}, 2.9-3.4)$ and 2.7 months $(95 \% \mathrm{CI}, 2.4-3.0)$, respectively $(P=0.017)$, and median OS times $=7.8$ months (95\% CI, 6.8-8.9) and 6.3 months $(95 \% \mathrm{CI}, 5.3-7.3)$, respectively $(P=0.036)$. No patient experienced Grade 4 toxicity. Combined third-line treatment with pemetrexed and DCs was marginally effective and well tolerated in patients with advanced ESCC. Serum miR-143 levels are a potential biomarker for predicting the efficacy of pemetrexed plus DCs in the treatment of ESCC.
\end{abstract}

Keywords: metastatic esophageal cancer, pemetrexed, dendritic cells, serum miR-143

\section{Introduction}

Esophageal cancer is an aggressive malignancy that is ranked eighth in the world in cancer incidence and sixth in cancer-related mortality. ${ }^{1}$ In Asian countries, most cases of esophageal cancer are squamous cell carcinoma, whereas adenocarcinomas constitute the majority of cases in Western countries. ${ }^{2}$ Palliative care is the only option for patients with advanced esophageal cancer, and a standard chemotherapy regimen for treating esophageal cancer has yet to be established. Although a combination of 5-fluorouracil and cisplatin administered by continuous infusion is the most commonly used first-line standard treatment regimen, only $\sim 30 \%$ of patients respond to this treatment, and the median survival time is only 6-10 months. ${ }^{3}$ Patients who fail first-line chemotherapy often experience a moderate progression-free survival (PFS) time when given a taxane-based (docetaxel or paclitaxel) second-line treatment. ${ }^{4,5}$ Although some patients who progress following first-line and secondline chemotherapy demonstrate a good performance status (PS) and remain suitable
Correspondence: Jing Tian

Department of Internal Medicine, Shan Dong Tumor Hospital, 440 Jiyan Road, Huaiyin District, Jinan 250I I7, People's Republic of China

$\mathrm{Tel}+8653167626351$

Fax +8653I 6762698 I

Email jielinqi@I26.com 
for chemotherapy, there is no currently established salvage treatment option.

Pemetrexed is a recently developed antifolate agent that appears to be well tolerated by patients who require further-line treatment. ${ }^{6}$ One study reported that pemetrexedbased radiotherapy was reasonably active and well tolerated when used to treat patients with locally advanced or metastatic esophageal cancer. ${ }^{7}$ Another study reported that second-line therapy with cetuximab plus pemetrexed was marginally effective and well tolerated in patients with advanced esophageal squamous cell carcinoma (ESCC). ${ }^{8}$ Dendritic cells (DCs) are potent antigen-presenting cells ${ }^{9}$ that stimulate effector T-cells, which present tumor antigens to T-lymphocytes and thereby induce an antitumor immune response. ${ }^{10}$ Moreover, some studies have shown that DCs are effective when used against esophageal cancer cells. ${ }^{11,12}$

MicroRNAs (miRNAs) are small noncoding RNAs that function as posttranscriptional gene regulators. ${ }^{13}$ Increasing evidence suggests that miRNAs can function as tumor suppressors or oncogenes and are involved in cancer pathogenesis and development of ESCC. ${ }^{14}$ Some recent studies have shown that miRNAs may have disease diagnostic and prognostic value. ${ }^{15}$ Furthermore, miR-143 has demonstrated an ability to suppress tumor growth, migration, and invasion in a model of ESCC. ${ }^{16}$ Another study showed that miR-143 could target the 3 '-UTR of STAT3 mRNA, which is a crucial factor in the JAK/STAT signaling pathway. ${ }^{17}$ In the present study, we evaluated the safety and efficacy of treatment with pemetrexed plus DCs in esophageal patients who were previously treated with first-line and second-line chemotherapy and also sought to identify a biomarker for predicting the efficacy of treatment with pemetrexed plus DCs.

\section{Patients and methods}

\section{Patients}

The study population consisted of 31 patients with histologically confirmed metastatic ESCC, who had failed treatment with firstline and second-line chemotherapy. All the enrolled patients had previously received pemetrexed plus dendritic cells between September 2011 and August 2013 at the Shandong Tumor Hospital and the Jining First Peoples Hospital. The patient selection criteria were age 18-75 years; Eastern Cooperative Oncology Group PS $\leq 2$; adequate hematological, hepatic, and adrenal functions (white blood cell count $\geq 4.0 \times 10^{9} / \mathrm{L}$; neutrophil count $\geq 1.5 \times 10^{9} / \mathrm{L}$; platelet count $\geq 100 \times 10^{9} / \mathrm{L}$; hemoglobin $\geq 10 \mathrm{~g} / \mathrm{dL} ;$ ALT and AST $\leq 2.5 \times$ upper limits of normal; total bilirubin $\leq 1.5 \times$ upper limits of normal; creatinine clearance $\geq 60 \mathrm{~mL} / \mathrm{min}$ or creatinine $\leq$ upper limits of normal); and life expectancy $>12$ weeks. All the patients had at least one measurable lesion based on CT scan. Exclusion criteria were massive pleural effusion or ascites, active concomitant malignancy, brain metastasis, pregnant, or lactating. The study was approved by the ethics committee of Shandong Ji Ning First People's Hospital, and all subjects provided a signed informed consent document. All patients underwent a qRTPCR assay to determine their serum miRNA-143 levels prior to initiation of treatment.

\section{DC preparation}

Peripheral blood mononuclear cells in a $50 \mathrm{~mL}$ blood specimen were enriched by density gradient centrifugation with FicollPaque. The enriched peripheral blood mononuclear cells were washed three times, resuspended in RPMI1640 medium containing granulocyte macrophage colony stimulating factor (1,000 U/mL; 4102-10; BioVision, Milpitas, CA, USA) and interleukin 4 (1,000 U/mL; Cellgenix, Heidelberg, Germany), and incubated at $37^{\circ} \mathrm{C}$ with $5 \% \mathrm{CO}_{2}$ for 24 hours. The culture medium was refreshed every 2 days. Following incubation, the cells were harvested, washed three times, and resuspended in $100 \mathrm{~mL}$ of $2.5 \%$ albumin in saline. The number of isolated DCs was $1.0 \times 10^{7}$.

\section{Treatment}

The patients were treated with pemetrexed $\left(500 \mathrm{mg} / \mathrm{m}^{2}\right)$ on day 1 , every 3 weeks. Prior to the first dose of pemetrexed, all patients had received a daily dose of folic acid for 7-14 days and an intramuscular injection of Vitamin B12 (1.0 mg) every 9 weeks. All patients were premedicated with dexamethasone (4 mg) on the day before, the day of, and the day after chemotherapy. Blood samples were collected from the patients 14 days after the chemotherapy and used to collect DCs. Lymphocytes were separated from the blood samples and cultured in vitro. DCs were administered to the patients by subcutaneous injection, and the treatment schedule is shown in Table 1. The treatment regimen was continued until disease progression, unacceptable toxicity occurred, or the patient refused treatment.

Table I Treatment schedule

\begin{tabular}{llll}
\hline Day & $\begin{array}{l}\text { Treatment } \\
\text { procedure }\end{array}$ & $\begin{array}{l}\text { Route of } \\
\text { administration }\end{array}$ & Injection site \\
\hline 0 & Blood acquisition & Cubital vein & N/A \\
0 & Pemetrexed & Intravenous infusion & Peripheral vein \\
7 & DCs & Subcutaneous injection & Inguinal region \\
I4 & DCs & Subcutaneous injection & Inguinal region \\
2 I & DCs & Subcutaneous injection & Inguinal region \\
\hline
\end{tabular}

Abbreviation: DCs, dendritic cells. 


\section{Evaluation and statistical analysis}

After two cycles of treatment, a CT scan was performed, and tumor response was assessed according to the Response Evaluation Criteria in Solid Tumors (RECIST, Version 1.0).

Toxicity was graded according to the National Cancer Institute Common Terminology Criteria for Adverse Events version 3.0 (NCI-CTCAE). Progression-free survival (PFS) and overall survival (OS) times were calculated as the time span from the day of initiation of treatment with pemetrexed plus DCs until disease progression, all cause death, or completion of the last follow-up evaluation. PFS and OS times were analyzed using the Kaplan-Meier method, and SPSS for Windows software (Version 16.0; SPSS Inc., Chicago, IL, USA).

\section{Results}

\section{Patient characteristics}

All patients in our study were diagnosed with stage IV squamous cell carcinoma, who had previously accepted chemotherapy with 5-fluorouracil plus platinum as first-line treatment and taxane-based chemotherapy as second-line treatment. Among the 31 enrolled patients, 51.6\% had distant lymph node metastases, $25.8 \%$ had lung metastases, and $16.2 \%$ had liver metastases. Thirty patients had at least a moderate PS, and one patient had a Grade 0 PS. Some demographic and clinical characteristics of the 31 enrolled patients are summarized in Table 2.

Table 2 Patient characteristics

\begin{tabular}{|c|c|c|}
\hline Factor & Patients, n & Patients, \% \\
\hline Median age (range) & 57.0 years (38-68 years) & \\
\hline \multicolumn{3}{|l|}{ Sex } \\
\hline Male & 18 & 58.1 \\
\hline Female & 13 & 41.9 \\
\hline \multicolumn{3}{|l|}{ Performance status } \\
\hline 0 & 0 & \\
\hline I & 17 & 54.8 \\
\hline 2 & 14 & 45.2 \\
\hline \multicolumn{3}{|l|}{ Histology } \\
\hline Squamous cell carcinoma & 31 & 100 \\
\hline \multicolumn{3}{|l|}{ First-line regimen } \\
\hline 5-FU-cisplatin & 25 & 80.6 \\
\hline 5-FU-nedaplatin & 6 & 19.4 \\
\hline \multicolumn{3}{|l|}{ Second-line regimen } \\
\hline Docetaxel & 19 & 61.3 \\
\hline Paclitaxel & 12 & 38.7 \\
\hline \multicolumn{3}{|l|}{ Metastasis sites } \\
\hline Distant lymph nodes & 16 & 51.6 \\
\hline Lung & 8 & 25.8 \\
\hline Liver & 5 & 16.2 \\
\hline Lung and liver & 2 & 6.4 \\
\hline
\end{tabular}

Note: Performance status measured using Eastern Cooperative Oncology Group criteria.

Abbreviation: 5-FU, 5-fluorouracil.
Table 3 Patient response to treatment

\begin{tabular}{ll}
\hline Response & $\begin{array}{l}\text { Number of patients (\%); } \\
\text { survival }\end{array}$ \\
\hline Complete response & 0 \\
Partial response & $3(10.0 \%)$ \\
Stable disease & $10(33.3 \%)$ \\
Progressive disease & $17(56.7 \%)$ \\
Median PFS & 2.9 months $(95 \% \mathrm{Cl}, 2.7-3.2)$ \\
Median OS & 7.1 months $(95 \% \mathrm{Cl}, 6.4-7.9)$ \\
Median PFS of high miR-I43 & 3.2 months $(95 \% \mathrm{Cl}, 2.9-3.4)$ \\
expression patients & \\
$\begin{array}{l}\text { Median PFS of low miR-I43 } \\
\text { expression patients }\end{array}$ & 2.7 months $(95 \% \mathrm{Cl}, 2.4-3.0)$ \\
Median OS of high miR-I43 & 7.8 months $(95 \% \mathrm{Cl}, 6.8-8.9)$ \\
expression patients & \\
$\begin{array}{l}\text { Median OS of low miR-I43 } \\
\text { expression patients }\end{array}$ & 6.3 months $(95 \% \mathrm{Cl}, 5.3-7.3)$ \\
\hline
\end{tabular}

Abbreviations: OS, overall survival; PFS, progression-free survival; $\mathrm{Cl}$, confidence interval.

\section{Response}

One patient in our study refused to accept treatment with pemetrexed plus DCs; however, 30 patients accepted at least two cycles of such treatment. Among the 30 patients who were evaluated for their response to treatment, three (10.0\%) showed a partial response, ten (33.3\%) had stable disease, and $17(56.7 \%)$ had progressive disease. No patient achieved a complete response. The overall response rate was $10.0 \%$ (Table 3). The median PFS time was 2.9 months $(95 \% \mathrm{CI}$, 2.7-3.2), and the median OS time was 7.1 months $(95 \% \mathrm{CI}$, 6.4-7.9; Figure 1). The PFS and OS times of patients significantly differed based on whether they had a high or low level of miR-143 expression in their blood serum. The median PFS times among patients with high and low levels of miR-143 expression were 3.2 months (95\% CI, 2.9-3.4) and 2.7 months

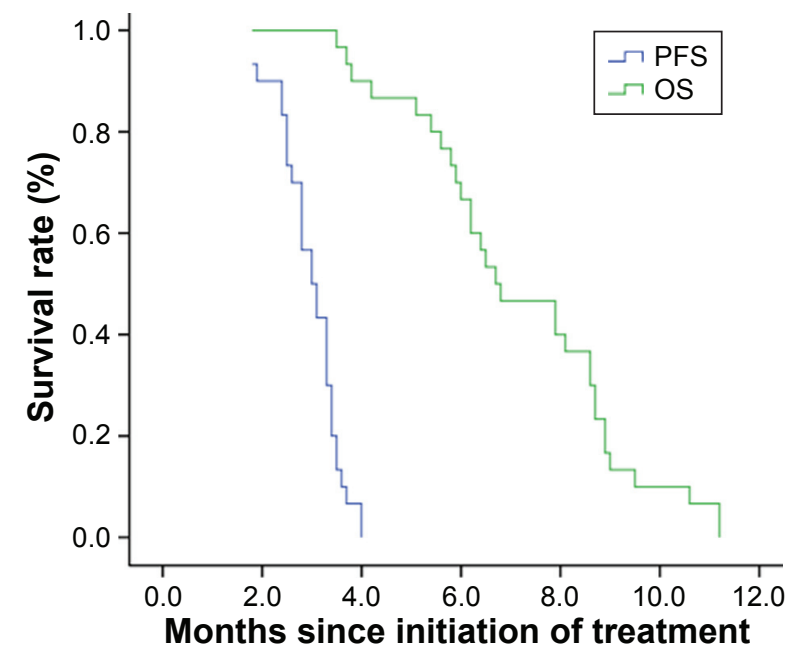

Figure I PFS and OS survival times in the study population. Abbreviations: OS, overall survival; PFS, progression-free survival. 


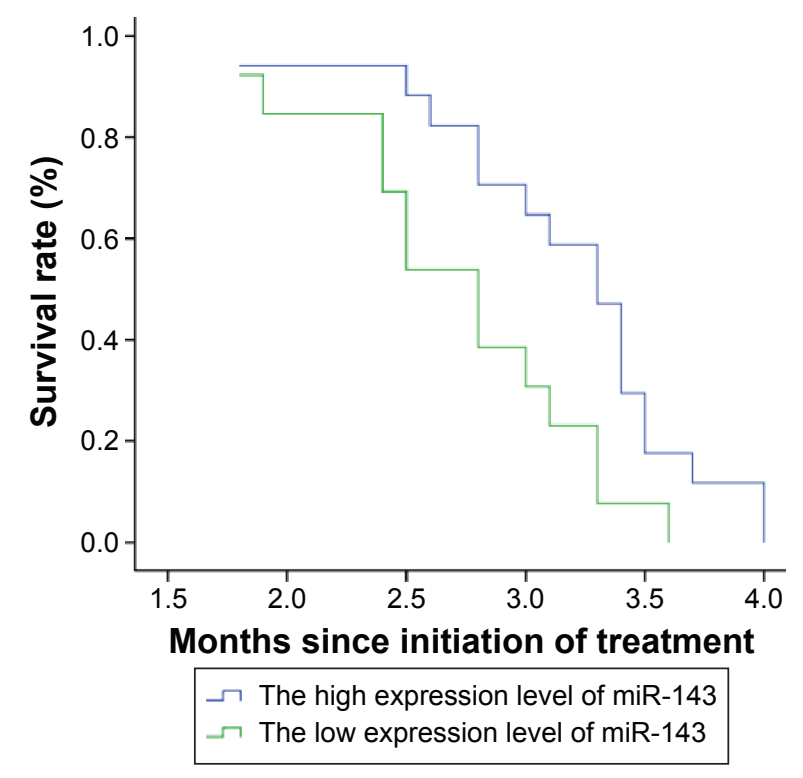

Figure 2 PFS times of patients with high and low levels of miR-I43 expression. Abbreviation: PFS, progression-free survival.

(95\% CI, 2.4-3.0; log-rank =0.017), respectively (Figure 2). The median OS times among patients with high and low levels of miR-143 expression were 7.8 months (95\% CI, 6.8-8.9) and 6.3 months (95\% CI, 5.3-7.3; log-rank $=0.036$ ), respectively (Figure 3).

\section{Toxicity}

All patients in our study displayed a good tolerance to treatment, and there was no incidence of Grade 4 toxicity. The main hematological toxicities were leukocytopenia (eight patients experienced Grade 1, four patients experienced Grade 2, and

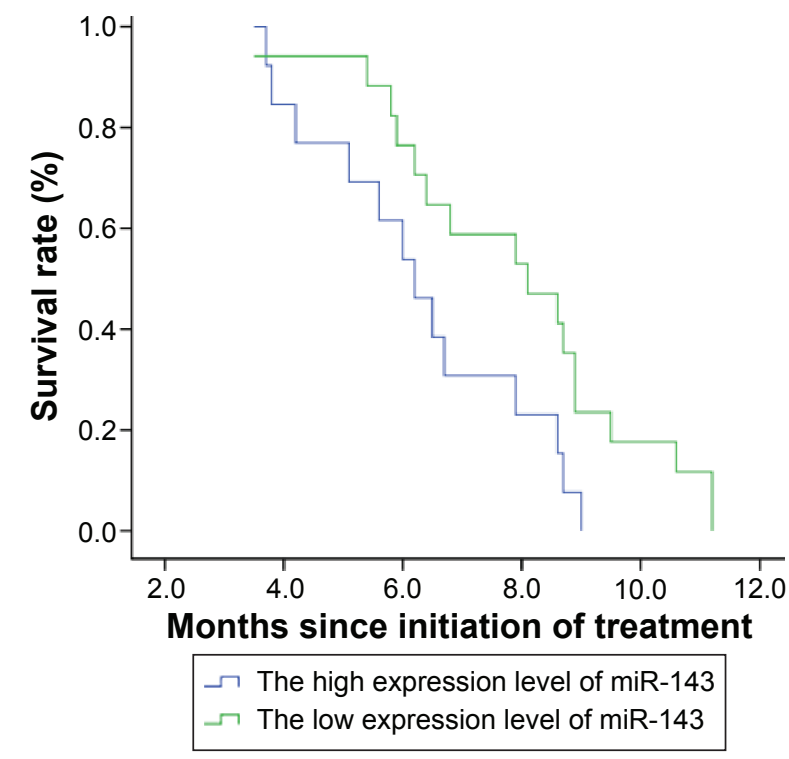

Figure 3 OS times of patients with high and low levels of miR-143 expression. Abbreviation: OS, overall survival.
Table 4 Treatment-related toxicities

\begin{tabular}{lllll}
\hline Toxicity & $\begin{array}{l}\text { Grade I, } \\
\text { n (\%) }\end{array}$ & $\begin{array}{l}\text { Grade 2, } \\
\text { n (\%) }\end{array}$ & $\begin{array}{l}\text { Grade 3, } \\
\text { n (\%) }\end{array}$ & $\begin{array}{l}\text { Grade 4, } \\
\text { n (\%) }\end{array}$ \\
\hline Leukocytopenia & $8(26.7)$ & $4(13.3)$ & $5(16.7)$ & 0 \\
Neutropenia & $7(23.3)$ & $4(13.3)$ & $6(20.0)$ & 0 \\
Thrombocytopenia & $3(10.0)$ & $5(16.7)$ & $3(10.0)$ & 0 \\
Anemia & $9(30.0)$ & $7(23.3)$ & $5(16.7)$ & 0 \\
Fever & $2(6.7)$ & $3(10.0)$ & 0 & 0 \\
Diarrhea & $4(13.3)$ & $2(6.7)$ & 0 & 0 \\
Nausea/vomiting & $7(23.3)$ & $4(13.3)$ & I (10.0) & 0 \\
Constipation & $5(16.7)$ & $3(10.0)$ & 0 & 0 \\
Fatigue & $5(16.7)$ & $9(30.0)$ & $6(20.0)$ & 0 \\
ALT/AST & $4(6.9)$ & $3(10.0)$ & 0 & 0 \\
Neurotoxicity & $6(20.0)$ & $9(30.0)$ & 0 & 0 \\
\hline
\end{tabular}

Note: Toxicity was graded according to the National Cancer Institute Common Terminology Criteria for Adverse Events version 3.0 (NCl-CTCAE).

Abbreviations: ALT, glutamic-pyruvic transaminase; AST, glutamic oxalacetic transaminase.

five patients experienced Grade 3), neutropenia (six patients experienced Grade 3), anemia (nine patients experienced Grade 1, seven patients experienced Grade 2, and five patients experienced Grade 3), and thrombocytopenia. The nonhematological toxicities included: nausea/vomiting, fatigue, diarrhea, fatigue, fever, constipation, and neurotoxicity. Five patients developed a fever after receiving DCs, and these events were considered to be drug-related (Table 4).

\section{Discussion}

Patients with metastatic esophageal carcinoma have a poor clinical prognosis, and there is no effective chemotherapeutic for treating the disease. However, some patients who fail first- and second-line treatment have a high PS and require an effective third-line chemotherapy regimen. ${ }^{18}$

A previous Phase I study showed that the maximum tolerated dose of pemetrexed was $500 \mathrm{mg} / \mathrm{m}^{2} .{ }^{8}$ Jatoi et al ${ }^{19}$ performed a Phase II study that employed a preoperative regimen consisting of pemetrexed, carboplatin, and radiation followed by surgery in treatment of locally advanced esophageal cancer and gastroesophageal junction tumors and reported that the median survival time of 22 patients who underwent a complete cancer resection was 17.8 months. DCs are specialized antigen-presenting cells that are involved in innate and adaptive immune responses. Some studies have shown that DCs play a crucial role in any tumor-specific immune response and are involved in the initiation of tumor-specific immunity and the generation of immune effect functions. Some Phase I, Phase II, and Phase III clinical trials have evaluated the effectiveness of ex vivo DC-loaded vaccines as anticancer immunotherapeutic agents against several types of malignancies. ${ }^{20}$ Ueda et $\mathrm{al}^{21}$ reported induction of a peptide-specific immune 
response in patients with primary malignant melanoma of the esophagus that had previously received immunotherapeutic treatment with DCs pulsed with MAGE peptides. Kono et $\mathrm{al}^{22}$ analyzed data from a multicenter Phase II clinical study of 60 patients with advanced esophageal cancer and reported that the immune response induced by vaccination with multiple peptides was associated with an improved clinical prognosis. In the present study, third-line treatment with pemetrexed plus dendritic cells was well tolerated by patients with metastatic ESCC. Most esophageal cancer patients who fail first- and second-line treatment have a poor PS, and no patient in our study had an Eastern Cooperative Oncology Group PS of 0. The PFS and OS times of our patients significantly differed based on whether they showed a high or low level of miR143 expression in their blood serum. Some previous studies reported that patient PS was significantly associated with both PFS and OS times. ${ }^{23,24}$ One study provided evidence that miR143 may suppress esophageal cancer by inhibiting increases in ERK5 protein levels. ${ }^{16}$ A majority of examined tumor tissues will show a significantly lower level of miR-143 expression when compared with such levels of nontumor tissues. ${ }^{25}$ One study demonstrated that a high level of miR-143 expression is predictive of a favorable outcome for ESCC patients and that miR-143 represses the cell cycle and epithelial-mesenchymal transition signaling pathways by targeting STAT3. ${ }^{26}$

One trial that investigated S-1 monotherapy as second- or third-line chemotherapy for nonresectable and recurrent ESCC found complete response, partial response, stable disease, and progressive disease rates of 5\% (one patient), 20\% (four patients), 35\% (seven patients), and 40\% (eight patients), respectively. Additionally, two cases $(10 \%)$ of anemia, one case $(5 \%)$ of leukopenia, three cases $(15 \%)$ of fatigue, and three cases (15\%) of diarrhea occurred as Grade 3 toxicities. The median PFS time in that study was 100 days, and the median OS time was 330 days. ${ }^{27}$ A study of pemetrexedbased chemotherapy used in treatment of patients with locally advanced or metastatic cancers showed that among eleven patients with advanced esophageal cancer who received the pemetrexed-based regimen as third-line treatment, two patients achieved a partial response, one showed stable disease, and the remaining eight patients showed progressive disease. ${ }^{28}$

\section{Conclusion}

Third-line treatment with pemetrexed plus dendritic cells was well tolerated by patients with ESCC, and our results suggest that cancer patients who show a high level of miR-143 expression in their blood serum may benefit from this combined treatment strategy. The efficacy that our combined treatment showed in ESCC patients must be confirmed in future studies with larger patient numbers.

\section{Acknowledgment}

The study was supported in part by 81301936 from National Nature Science Foundation of China.

\section{Disclosure}

The authors report no conflicts of interest in this work.

\section{References}

1. Tang WR, Fang JY, Wu KS, Shi XJ, Luo JY, Lin K. Epidemiological characteristics and prediction of esophageal cancer mortality in China from 1991 to 2012. Asian Pac J Cancer Prev. 2014;15(16):6929-6934.

2. Siegel R, Ward E, Brawley O, Jemal A. Cancer statistics, 2011: the impact of eliminating socioeconomic and racial disparities on premature cancer deaths. CA Cancer J Clin. 2011;61(4):212-236.

3. Lorenzen S, Schuster T, Porschen R, et al. Cetuximab plus cisplatin-5fluorouracil versus cisplatin-5-fluorouracil alone in first-line metastatic squamous cell carcinoma of the esophagus: a randomized phase II study of the Arbeitsgemeinschaft Internistische Onkologie. Ann Oncol. 2009; 20(10):1667-1673.

4. Akutsu Y, Shuto K, Kono T, et al. A phase I/II study of second-line chemotherapy with fractionated docetaxel and nedaplatin for 5-FU/ cisplatin-resistant esophageal squamous cell carcinoma. Hepatogastroenterology. 2012;59(119):2095-2098.

5. Moriwaki T, Kajiwara T, Matsumoto T, et al. Survival analysis of platinum-refractory patients with advanced esophageal cancer treated with docetaxel or best supportive care alone: a retrospective study. Dis Esophagus. 2014;27(8):737-743.

6. Genestreti G, Grossi F, Genova C. Third- and further-line therapy in advanced non-small-cell lung cancer patients: an overview. Future Oncol. 2014;10(13):2081-2096.

7. Tian GY, Miu M, Huang XE. Systematic analysis of pemetrexedbased chemoradiotherapy for patients with locally advanced or metastatic esophageal cancer. Asian Pac J Cancer Prev. 2014;15(19): 8475-8478.

8. Tian J, Shang M, Shi SB, Han Y, Xu J. Cetuximab plus pemetrexed as second-line therapy for fluorouracil-based pre-treated metastatic esophageal squamous cell carcinoma. Cancer Chemother Pharmacol. 2015;76(4):829-834.

9. Banchereau J, Steinman RM. Dendritic cells and the control of immunity. Nature. 1998;392(6673):245-252.

10. Wang X, Yu W, Li H, et al. Can the dual-functional capability of CIK cells be used to improve antitumor effects? Cell Immunol. 2014;287(1): $18-22$.

11. Milano F, Rygiel AM, Buttar N, et al. An ex vivo readout for evaluation of dendritic cell-induced autologous cytotoxic $\mathrm{T}$ lymphocyte responses against esophageal cancer. Cancer Immunol Immunother. 2007;56(12): 1967-1977.

12. Narita $M$, Kanda $T$, Abe $T$, et al. Immune responses in patients with esophageal cancer treated with SART1 peptide-pulsed dendritic cell vaccine. Int J Oncol. 2015;46(4):1699-1709.

13. Grishok A, Pasquinelli AE, Conte D, et al. Genes and mechanisms related to RNA interference regulate expression of the small temporal RNAs that control C. elegans developmental timing. Cell. 2001;106(1):23-34.

14. Zhang J, Cheng C, Yuan X, He JT, Pan QH, Sun FY. microRNA-155 acts as an oncogene by targeting the tumor protein 53 -induced nuclear protein 1 in esophageal squamous cell carcinoma. Int J Clin Exp Pathol. 2014;7(2):602-610.

15. Larne O, Martens-Uzunova E, Hagman Z, et al. miQ - a novel microRNA based diagnostic and prognostic tool for prostate cancer. Int J Cancer. 2013;132(12):2867-2875. 
16. Ni Y, Meng L, Wang L, et al. MicroRNA-143 functions as a tumor suppressor in human esophageal squamous cell carcinoma. Gene. 2013; 517(2):197-204.

17. Lee JH, Chiang SY, Nam D, et al. Capillarisin inhibits constitutive and inducible STAT3 activation through induction of SHP-1 and SHP-2 tyrosine phosphatases. Cancer Lett. 2014;345(1):140-148.

18. Syrigos KN, Zalonis A, Kotteas E, Saif MW. Targeted therapy for oesophageal cancer: an overview. Cancer Metastasis Rev. 2008;27(2): 273-288.

19. Jatoi A, Soori G, Foster NR, et al. Phase II study of preoperative pemetrexed, carboplatin, and radiation followed by surgery for locally advanced esophageal cancer and gastroesophageal junction tumors. J Thorac Oncol. 2010;5(12):1994-1998.

20. Vacchelli E, Vitale I, Eggermont A, et al. Trial watch: dendritic cellbased interventions for cancer therapy. Oncoimmunology. 2012;1(7): 1111-1134.

21. Ueda Y, Shimizu K, Itoh T, et al. Induction of peptide-specific immune response in patients with primary malignant melanoma of the esophagus after immunotherapy using dendritic cells pulsed with MAGE peptides. Jpn J Clin Oncol. 2007;37(2):140-145.

22. Kono K, Iinuma H, Akutsu Y, et al. Multicenter, phase II clinical trial of cancer vaccination for advanced esophageal cancer with three peptides derived from novel cancer-testis antigens. J Transl Med. 2012; $10: 141$.
23. Park SR, Kook M, Choi IJ, et al. Predictive factors for efficacy of cetuximab plus chemotherapy as salvage therapy in metastatic gastric cancer patients. Cancer Chemother Pharmacol. 2010;65(3):579-587.

24. Gold J, Goldman B, Iqbal S, et al. Cetuximab as second-line therapy in patients with metastatic esophageal adenocarcinoma. J Thorac Oncol. 2010;5(9):1472-1476.

25. Ansari MH, Irani S, Edalat H, Amin R, Mohammadi Roushandeh A. Deregulation of miR-93 and miR-143 in human esophageal cancer. Tumour Biol. 2016;37(3):3097-3103.

26. Liu J, Mao Y, Zhang D, et al. MiR-143 inhibits tumor cell proliferation and invasion by targeting STAT3 in esophageal squamous cell carcinoma. Cancer Lett. 2016;373(1):97-108.

27. Akutsu Y, Kono T, Uesato M. S-1 monotherapy as second- or third-line chemotherapy for unresectable and recurrent esophageal squamous cell carcinoma. Oncology. 2013;84(5):305-310.

28. Qian T, Huang XE. Study of pemetrexed-based chemotherapy for patients with locally advanced or metastatic cancers. Asian Pac J Cancer Prev. 2015;16(11):4791-4795.
OncoTargets and Therapy

\section{Publish your work in this journal}

OncoTargets and Therapy is an international, peer-reviewed, open access journal focusing on the pathological basis of all cancers, potential targets for therapy and treatment protocols employed to improve the management of cancer patients. The journal also focuses on the impact of management programs and new therapeutic agents and protocols on

\section{Dovepress}

patient perspectives such as quality of life, adherence and satisfaction. The manuscript management system is completely online and includes a very quick and fair peer-review system, which is all easy to use. Visit http://www.dovepress.com/testimonials.php to read real quotes from published authors. 